\title{
Solution-processed solar-charging power units made of organic photovoltaic modules and asymmetric super-capacitors
}

Yingzhi Jin, Lulu Sun, Leiqiang Qin, Yanfeng Liu, Zaifang Li, Yinhua Zhou and Fengling Zhang

The self-archived postprint version of this journal article is available at Linköping University Institutional Repository (DiVA):

http://urn.kb.se/resolve?urn=urn:nbn:se:liu:diva-176167

N.B.: When citing this work, cite the original publication.

Jin, Y., Sun, L., Qin, L., Liu, Y., Li, Z., Zhou, Y., Zhang, F., (2021), Solution-processed solar-charging power units made of organic photovoltaic modules and asymmetric super-capacitors, Applied Physics Letters, 118(20), 203902. https://doi.org/10.1063/5.0044652

Original publication available at:

https://doi.org/10.1063/5.0044652

Copyright: American Institute of Physics

http://www.aip.org/ 


\section{Solution-processed solar-charging power units made of organic photovoltaic modules and asymmetric super-capacitors}

Yingzhi Jin ${ }^{\mathrm{a}, \mathrm{c}}$, Lulu Sun ${ }^{\mathrm{b}}$, Leiqiang Qin ${ }^{\mathrm{a}}$, Yanfeng Liu ${ }^{\mathrm{a}}$, Zaifang $\mathrm{Li}^{\mathrm{c}, *}$, Yinhua Zhou ${ }^{\mathrm{b}, *}$, and Fengling Zhang $^{\mathrm{a}, *}$

${ }^{a}$ Department of Physics, Chemistry and Biology (IFM), Linköping University, SE-58183 Linköping, Sweden

${ }^{\mathrm{b}}$ Wuhan National Laboratory for Optoelectronics, Huazhong University of Science and Technology, Wuhan 430074, China

${ }^{\mathrm{c}}$ China-Australia Institute for Advanced Materials and Manufacturing, Jiaxing University, Jiaxing 314001, P. R. China

Authors to whom correspondence should be addressed: zaifang.li@zjxu.edu.cn, yh_zhou@hust.edu.cn, fengling.zhang@liu.se

\section{ABSTRACT}

Organic photovoltaics with the properties of flexibility, portability and printability are ideal candidates for low power consumption electronics such as the Internet of Things under indoor light conditions. In this work, an all solution-processed integrated photo-capacitor (IPC) consist of an organic photovoltaic module (OPVM) and an asymmetric super-capacitor (ASC) is demonstrated. The OPVM (PBDB-T:ITIC, $2.3 \mathrm{~cm}^{2}$ ) with PEDOT:PSS as the top electrode delivers a high power conversion efficiency of $6.7 \%$ with a voltage of $4.3 \mathrm{~V}$ (1 Sun). The ASC based on PEDOT:PSS and $\mathrm{Ti}_{3} \mathrm{C}_{2} \mathrm{~T}_{\mathrm{x}}$ electrodes shows a wide operation window of $1.5 \mathrm{~V}$ in the aqueous electrolyte with a high energy density of $28.7 \mu \mathrm{W} \mathrm{h} \mathrm{cm}{ }^{-2}$. Consequently, the IPC achieves a high output voltage of $3 \mathrm{~V}$ and outstanding overall efficiency of $6.0 \%$ (45000 flux), which shows excellent stability as the solar-charging power unit under room light (500 flux). Synergizing energy harvest and storage in a solution-processed robust, lightweight, low-cost organic IPC enables this solar-charging power unit wide potential applications in low powerconsumption portable electronics. 
The demand for renewable energy power has increased significantly with the dramatic increase in electricity demand in our daily life, especially for the Internet of Things. Batteries are commonly used for mobile electronics but need to be recharged with electricity from grids. Integrated photo-capacitor (IPC) consists of a photovoltaic device and a super-capacitor has been designed to have a dual-function of energy harvesting and storage in a single unit. The concept of IPC was first proposed in 2004 and developed rapidly in recent years. ${ }^{1-7}$ The working process of the IPC is that charges generated in the photovoltaic device under illumination are stored in the super-capacitor. Therefore, the IPCs could be utilized as solar-charging power units for grid-free energy supply whenever needed.

Compared to commercialized solar powered products, the unique advantages of the organic IPCs are solution-processed, lightweight, robust, and flexible, which make organic IPCs more suitable for portable and wearable electronics than those Si based commercialized solar powered products. The low cost of organic IPCs allows them integrated with the Internet of Things and affordable by broad consumers. In 2010, Srinivasan et al. demonstrated an IPC utilizing single-walled carbon nanotube network between the organic photovoltaic (OPV) and the super-capacitor. ${ }^{8}$ The low open-circuit voltage $\left(V_{\text {oc }}\right)$ of $0.6 \mathrm{~V}$ restricts the voltage window of the super-capacitor. In 2014, Peng et al. fabricated a wire-shaped IPC in which both the OPV and super-capacitor were developed with a Ti wire substrate. ${ }^{9}$ Although wire-shaped IPCs are flexible and wearable, the performances are lower than the planar structure. An IPC consisting of series-connected OPVs and graphene capacitor was reported by Amaratunga et al. in 2015. ${ }^{10}$ A high $V_{\text {oc }}$ of $5 \mathrm{~V}$ was obtained from eight series-connected OPVs with aluminium electrodes, which provide a large voltage window for the capacitor. In 2016, an IPC based on OPV was optimized for indoor light energy harvesting, exhibiting potential for autonomous application in various light conditions. Lee et al., combined a high-performance OPV based on PTB7-Th 
and $\mathrm{PC}_{71} \mathrm{BM}$ with a super-capacitor and a high overall efficiency ( $\left.\eta_{\text {overall }}\right)$ of $5.07 \%$ was achieved. ${ }^{11}$ Recently, Kenjiro Fukuda and Takao Someya demonstrated an ultra-thin (a thickness less than $50 \mu \mathrm{m}$ ) photo-charging device with a total efficiency approaching $6 \%$, which was prepared by integrating $3-\mu \mathrm{m}$-thick OPVs on $40 \mu \mathrm{m}$-thick carbon nanotube/polymer-based supercapacitors. ${ }^{12}$ In our previous work, we have demonstrated an IPC composed of a monolithic OPV and a capacitor with a free-standing poly(3,4ethylenedioxythiophene):poly(styrenesulfonate) (PEDOT:PSS) film as the common electrode. ${ }^{13}$ Recently, the power conversion efficiency (PCE) of OPVs is approaching $18 \%$ with non-fullerene acceptors (NFAs), ${ }^{14}$ which make them possible to further increase the $\eta_{\text {overall }}$ of the IPCs. Despite encouraging progress that has been achieved with IPCs based on OPVs, the low $\eta_{\text {overall }}$ with low output voltage is still limited their applications. Therefore, increasing the output voltage of the IPCs is urgently needed for exploring the practical application as solarcharging power units. To achieve a large voltage, both the energy harvesting and storage parts need to be designed. For the energy harvesting part, organic photovoltaic modules (OPVMs) with series-connected subunits are a good choice to increase the output voltage. For the energy storage part, asymmetric super-capacitors (ASCs) are selected due to the wider operation window and higher energy density than the symmetric ones. ${ }^{15}$ It is essential to choose different materials to construct the ASCs. Recently, $\mathrm{Ti}_{3} \mathrm{C}_{2} \mathrm{~T}_{\mathrm{x}}$ Mxene, a new class of $2 \mathrm{D}$ materials, is widely investigated as energy storage material due to the attractive properties including excellent conductivity, solution processable, and good flexibility. ${ }^{16-19}$ The high capacitance and low operation potential in the negative region make it an ideal cathode material.

In this work, a solar-charging power unit that enables continuous power supplying for a digital thermometer under room light illumination is achieved. The self-powering is realized via the integration of an all solution-processed OPVM and an ASC. For the OPVM, a PCE of $6.7 \%$ with a high voltage of $4.3 \mathrm{~V}$ is achieved (1 Sun condition). PEDOT:PSS film is laminated 
as the common electrode due to its high conductivity and capacitance. ${ }^{20-26}$ In the energy storage part, free-standing high conductive PEDOT:PSS and $\mathrm{Ti}_{3} \mathrm{C}_{2} \mathrm{~T}_{\mathrm{x}}$ MXene films are used as anode and cathode electrodes, respectively. The ASC shows a wide operation window of $1.5 \mathrm{~V}$ in the aqueous electrolyte with a high energy density of $28.7 \mu \mathrm{W} \mathrm{h} \mathrm{cm}{ }^{-2}$. More importantly, the IPC demonstrates outstanding performance with an overall efficiency of $6.0 \%$ and a high output voltage of $3 \mathrm{~V}$ under the illumination of a white light-emitting diode (LED) light source (45000 lux), which is among the highest value of reported IPCs based on OPVs, with outstanding stability under room light. Our work demonstrates the potential of the solution-processed IPC on the application of in-door solar-charging powered portable electronics.

The solution-processed OPVM with 5 series-connected units is displayed in Fig. 1a. The $J-V$ characteristic of the OPVM is shown in Table 1 and Fig. 1b. The OPVM (the active area is $\left.2.3 \mathrm{~cm}^{2}\right)$ with 5 units shows an open-circuit voltage $\left(V_{\mathrm{oc}}\right)$ of $4.32 \mathrm{~V}$, a short-circuit current density $\left(J_{\mathrm{sc}}\right)$ of $2.4 \mathrm{~mA} \mathrm{~cm} \mathrm{~cm}^{-2}$, a fill factor (FF) of 0.64 and a PCE of $6.7 \%$. The average $V_{\mathrm{oc}}$ of each subcell is around $0.86 \mathrm{~V}$. For comparison, the single cell with the device configuration of ITO/ZnO/PBDB-T:ITIC/MoO$/ \mathrm{Al}$ is also fabricated. The device displays a performance of $V_{\mathrm{oc}}$ $=0.88, J_{\mathrm{sc}}=15.23 \mathrm{~mA} \mathrm{~cm}{ }^{-2}, \mathrm{FF}=0.65$ and PCE $=8.72 \%($ Table 1$)$. The decrease of $J_{\mathrm{sc}}$ in OPVM compared to the reference single device might be attributed to the higher series resistance $\left(R_{\mathrm{S}}\right)$.

TABLE 1. Photovoltaic performance of OPVM and single cells.

\begin{tabular}{cccccc}
\hline Device type & $\begin{array}{c}V_{\text {oc }} \\
(\mathrm{V})\end{array}$ & $\begin{array}{c}J_{\mathrm{sc}} \\
(\mathrm{mA} \mathrm{cm}-2)\end{array}$ & FF & $\begin{array}{c}\text { PCE } \\
(\%)\end{array}$ & $\begin{array}{c}R_{\mathrm{s}} \\
\left(\Omega \mathrm{cm}^{2}\right)\end{array}$ \\
\hline & 4.32 & 2.4 & 0.64 & 6.7 & \\
OPVM with 5 cells (PEDOT:PSS) & $(4.30 \pm 0.05)$ & $(2.3 \pm 0.2)$ & $(0.63 \pm 0.02)$ & $(6.4 \pm 0.3)$ & 220 \\
Single cell ( $\left.\mathrm{MoO}_{3} \& \mathrm{Al}\right)$ & & & & & \\
& 0.88 & 15.23 & 0.65 & 8.72 & 4.5 \\
\hline
\end{tabular}


To construct an ASC with a wide potential window, a positive pseudocapacitive material (free-standing PEDOT:PSS film) is required to combine with a negative pseudocapacitive material (free-standing $\mathrm{Ti}_{3} \mathrm{C}_{2} \mathrm{~T}_{\mathrm{x}}$ film). In order to evaluate the electrochemical properties of the free-standing PEDOT:PSS and $\mathrm{Ti}_{3} \mathrm{C}_{2} \mathrm{~T}_{\mathrm{x}}$ electrode, cyclic voltammetry $(\mathrm{CV})$ and galvanostatic charge/discharge (GCD) measurements are conducted in a three-electrode setup using $1 \mathrm{M}$ $\mathrm{H}_{2} \mathrm{SO}_{4}$ as electrolyte(Supporting Information Fig. S1-2). PEDOT:PSS and $\mathrm{Ti}_{3} \mathrm{C}_{2} \mathrm{~T}_{\mathrm{x}}$ electrodes show complementary working potential and outstanding electrochemical performance $(214 \mathrm{mF}$ $\mathrm{cm}^{-2}$ for PEDOT:PSS and $384 \mathrm{mF} \mathrm{cm}^{-2}$ for $\mathrm{Ti}_{3} \mathrm{C}_{2} \mathrm{~T}_{\mathrm{x}}$ ). Therefore, solid-state ASCs are fabricated based on the two electrodes, as illustrated in Fig. 2a. To optimize the electrochemical performance of the ASCs, the thicknesses of the two electrodes are tuned to balance the charges. The CV curves of the PEDOT:PSS $(-0.2 \sim 0.8 \mathrm{~V})$ and $\mathrm{Ti}_{3} \mathrm{C}_{2} \mathrm{~T}_{\mathrm{x}}(-0.7 \sim 0.2 \mathrm{~V})$ electrodes at the scan rate of $50 \mathrm{mV} \mathrm{s}^{-1}$ are shown in Fig. $2 \mathrm{~b}$, indicating that a similar amount of charges were stored in each electrode. The cell voltage of solid-state ASCs can be tuned from 1 to $1.8 \mathrm{~V}$ at a scan rate of $100 \mathrm{mV} \mathrm{s}^{-1}$ (Fig. 2c), which increases the energy density compared to the symmetric devices. The electrochemical performance of the ASCs is investigated by CV and GCD measurements. As shown in Fig. 2d, the ASCs can be operated at various scan rates in the potential window from 0 to $1.5 \mathrm{~V}$. The nearly rectangle shape of the $\mathrm{CV}$ curves even at a high scan rate of $200 \mathrm{mV} \mathrm{s}^{-1}$ indicates the low resistance and excellent capacitive properties. The GCD profiles of the ASCs at different current densities are shown in Fig. 2e. The nearly symmetric shapes of these curves indicate high reversibility of the charging/discharging processes of the device. The areal capacitances of the ASCs under different current densities are presented in Fig. 2f. The areal capacitance of the ASCs reaches $93 \mathrm{mF} \mathrm{cm}^{-2}$ at a current density of $0.25 \mathrm{~mA} \mathrm{~cm}^{-2}$ and remains $89 \%$ of initial capacitance at the current density of $3 \mathrm{~mA}$ $\mathrm{cm}^{-2}$. 
The Ragone plot (energy density $\left(E_{\mathrm{Ca}}\right)$ vs. power density $\left(P_{\mathrm{Ca}}\right)$ ) of the ASCs device is shown in Fig. S3a. The energy and power densities are determined from the discharge curves at different current densities according to Equation 1 and 2.

$$
\begin{gathered}
E_{\mathrm{Ca}}=\frac{1}{2 \times 3600} C_{\mathrm{A}}(\Delta V)^{2} \\
P_{\mathrm{Ca}}=\frac{E_{\mathrm{Ca}}}{\Delta t} \times 3600
\end{gathered}
$$

where $E_{\mathrm{Ca}}$ is in the unit of $\left.(\mathrm{mW} \mathrm{h} \mathrm{cm})^{-2}\right), C_{\mathrm{A}}$ is the areal capacitance $\left(\mathrm{mF} \mathrm{cm} \mathrm{cm}^{-2}\right), \Delta V$ is the operating voltage window $(\mathrm{V}), P_{\mathrm{Ca}}$ is in the unit of $\left(\mathrm{mW} \mathrm{cm}^{-2}\right)$, and $\Delta t$ is the discharge time (s). The energy density of the ASCs can reach up to $28.7 \mu \mathrm{W} \mathrm{h} \mathrm{cm}{ }^{-2}$ at a power density of $187 \mu \mathrm{W}$ $\mathrm{cm}^{-2}$, and remain $23.5 \mu \mathrm{W} \mathrm{h} \mathrm{cm}{ }^{-2}$ at a power density of $2146 \mu \mathrm{W} \mathrm{cm} \mathrm{cm}^{-2}$. The cycling stability of the ASCs is evaluated through GCD measurements at the current density of $4 \mathrm{~mA} \mathrm{~cm}^{-2}$ (Fig. S3b). The ASCs exhibited excellent cycling stability with capacitance retention of $82 \%$ over 5000 cycles. To meet the high-voltage applications, two ASCs connected in series can achieve an output voltage of $3 \mathrm{~V}$. The $\mathrm{CV}$ and GCD results are shown in Fig. S4. These results demonstrate that the ASCs possess outstanding electrochemical stability, which is crucial for practical applications. Furthermore, the leakage current and self-discharge characteristics of the series-connected ASCs are evaluated (Fig. S5). The leakage characteristics are measured by holding at a constant voltage for $10 \mathrm{~min}$ and measuring the corresponding current. As shown in Fig. S5a, the leakage current increases with potential and a value of $\sim 33 \mu \mathrm{A} \mathrm{cm}{ }^{-2}$ for $3 \mathrm{~V}$, which indicates a small leakage current. After being charged at $3 \mathrm{~V}$ for $10 \mathrm{~min}$, the potential of the device exhibits a rapid decrease in the first hour and gradually decreases to $0.83 \mathrm{~V}$ after $5 \mathrm{~h}$, revealing a low self-discharge characteristic. The low leakage current and high capacitance make them suitable for integration with the OPVM.

To achieve simultaneous energy harvesting and storage in a single device, OPVM and ASCs are integrated by employing PEDOT:PSS film as a common electrode. The structure of 
the IPC is illustrated in Fig. 3. The photo-charging and discharging of the IPC is investigated under an LED illumination. The illuminance of the LED $\left(E_{\mathrm{V}}\right.$, in the unit of lux $)$ could be calculated by the following Equation (3) 27 :

$$
E_{V}=K_{m} \int E_{\lambda}(\lambda) \times V(\lambda) d \lambda
$$

Where $K_{\mathrm{m}}$ is the maximum photopic luminous efficacy $\left(683 \mathrm{~lm} \mathrm{~W} \mathrm{~W}^{-1}\right), E_{\lambda}$ is the emission power spectrum, and $V(\lambda)$ is the spectral luminosity function (Fig. S6).

The emission power spectrum of the LED at 45000 lux is shown in Fig. 4a, and the light power intensity is $13.7 \mathrm{~mW} \mathrm{~cm}^{-2}$. As shown in Fig. $4 \mathrm{~b}$, the ASCs can be charged to $3 \mathrm{~V}$ in about $100 \mathrm{~s}$ under the LED illumination at 45000 lux, suggesting a good charge transport of the IPC. Then, the IPC was discharged at various current densities from 0.25 to $1.5 \mathrm{~mA} \mathrm{~cm}^{-2}$ after turn off the LED light. The areal capacitances of the ASCs in the IPCs are calculated according to the discharge profile in Fig. 4b, which are approaching the performance of unintegrated ASCs (Fig. 4c), indicating the successful integration of the energy storage and energy harvesting devices. Furthermore, the photo-charge and discharge of the IPC is evaluated at low illuminance (1000 lux). The emission power spectrum of the LED at 1000 lux is shown in Fig. S7a, and the light power intensity is $304.6 \mu \mathrm{W} \mathrm{cm}$. $^{-2}$ As shown in Fig. $4 \mathrm{~d}$, with decreasing illuminance, the photo-charge time increased to around $20 \mathrm{~min}(1230 \mathrm{~s})$ and the charge potential decreased to 1.5 V. This is due to the decrease in the output power of the OPVM under low illuminance. The overall conversion efficiency ( $\left.\eta_{\text {overall }}\right)$ of the IPC is calculated from Equation (4), which strongly depends on the incident light power density.

$$
\eta_{\text {overall }}=E_{\mathrm{Ca}} \times A_{\mathrm{Ca}} / P_{\text {in }} \times t \times A_{\mathrm{OPVM}}
$$

where $A_{\text {Ca }}$ is the total area of ASC, $P_{\text {in }}$ is incident light power density, $\mathrm{t}$ is the photo-charge time, Aopvm is the effective area of OPVM. 
As shown in Fig. 4e and S8b, the maximum $\eta_{\text {overall }}$ for the IPC under 45000 and 1000 lux illuminance were $6.0 \%$ and $4.8 \%$, respectively. The maximum $\eta_{\text {overall }}$ of $6.0 \%$ of our system is one of the highest values amongst the state-of-the-art organic IPC. A comparison of the $\eta_{\text {overall }}$ and output voltage between our system and other IPC systems are listed in Table S1. Therefore, our IPC shows high potential as a solar-charging power unit for powering suitable electronics.

The IPC as a solar-charging power unit would be suitable for suppressing fluctuations of the incident light, and powering mini-power electronic devices. Here, a digital thermometer was selected to illustrate the application of our solar-charging power unit (Fig. 4f). After photocharging, the IPC could power the digital thermometer for about 8 min (Fig. S8). Moreover, under low illuminance of light intensity about 500 lux (the intensity is comparable with that in a library or shopping mall), the IPC could power the digital thermometer (Fig. S9). During about $5 \mathrm{~h}$ testing, there was no obvious change in the display contrast of the digital thermometer, which indicated the high stability of the IPC. Consequently, one potential application of the IPC is to supply power for price tags of goods in shopping malls.

In conclusion, solution-processed IPC consisting of an OPVM and ASCs is demonstrated to realize the dual functions of energy harvesting and storage. The OPVM with PEDOT:PSS as top electrodes had a high output voltage of $4.3 \mathrm{~V}$ and a PCE of $6.7 \%$. The ASCs based on PEDOT:PSS and $\mathrm{Ti}_{3} \mathrm{C}_{2} \mathrm{~T}_{\mathrm{x}}$ electrodes showed a high areal capacitance of $93 \mathrm{mF} \mathrm{cm}{ }^{-2}$, provided a maximum power density of $2146 \mu \mathrm{W} \mathrm{cm} \mathrm{c}^{-2}$, and maximum energy density of $28.7 \mu \mathrm{W} \mathrm{h} \mathrm{cm}{ }^{-2}$. Accordingly, the IPC delivered a high output voltage of $3 \mathrm{~V}$ and an outstanding $\eta_{\text {overall }}$ of $6.0 \%$ at a discharge current density of $0.25 \mathrm{~mA} \mathrm{~cm}^{-2}$, demonstrating one of the highest performance among state-of-the-art organic IPC. Furthermore, the IPC could act as a solar-charging power unit to power a digital thermometer under low illuminance with excellent stability. Therefore, the synergy of energy harvesting and storage is realized in our system, which providing a possible way for real applications as solar-charging powered electronics. 


\section{SUPPLEMENTARY MATERIAL}

See the supplementary material for the electrochemical properties of the free-standing PEDOT:PSS and MXene electrodes, the CV, GCD, Ragone plots, cyclic stability, selfdischarge of the ASCs, spectral luminosity function, applications of IPCs, performance comparison. The experimental section describes the preparation and characterization of electrodes and devices.

The work is supported by Swedish Research Council (2017-04123), the Swedish Government Strategic Research Area in Materials Science on Functional Materials at Linköping University (Faculty Grant SFO-Mat-LiU No 200900971), the Knut and Alice Wallenberg Foundation (2016.0059) through the project "Mastering Morphology for Solution-borne Electronics" and China Scholarship Council (CSC). Z. L. acknowledges the financial support from Jiaxing Public Welfare Research Program (No. 2019AY11007).

\section{DATA AVAILABILITY}

The data that support the findings of this study are available from the corresponding author upon reasonable request.

\section{REFERENCES}

${ }^{1}$ T. Miyasaka and T. N. Murakami, Appl. Phys. Lett. 85, 3932 (2004).

2J. Liang, G. Zhu, C. Wang, Y. Wang, H. Zhu, Y. Hu, H. Lv, R. Chen, L. Ma, T. Chen, Z. Jin, and J. Liu, Adv. Energy Mater. 7, 1601208 (2017).

${ }^{3}$ A. Scalia, A. Varzi, A. Lamberti, E. Tresso, S. Jeong, T. Jacob, and S. Passerini, Sustainable Energy Fuels 2, 968 (2018).

${ }^{4}$ C. Li, S. Cong, Z. Tian, Y. Song, L. Yu, C. Lu, Y. Shao, J. Li, G. Zou, M. H. Rümmeli, S. Dou, J. Sun, and Z. Liu, Nano Energy 60, 247 (2019).

${ }^{5}$ B.-M. Kim, M.-H. Lee, V. S. Dilimon, J. S. Kim, J. S. Nam, Y.-G. Cho, H. K. Noh, D.-H. Roh, T.-H. Kwon, and H.-K. Song, Energy Environ. Sci. 13, 1473 (2020).

${ }^{6}$ L. Qin, J. Jiang, Q. Tao, C. Wang, I. Persson, M. Fahlman, P. O. Å. Persson, L. Hou, J. Rosen, and F. Zhang, J. Mater. Chem. A 8, 5467 (2020).

${ }^{7}$ Q. Zeng, Y. Lai, L. Jiang, F. Liu, X. Hao, L. Wang, and M. A. Green, Adv. Energy Mater. 10, 1903930 (2020).

${ }^{8}$ G. Wee, T. Salim, Y. M. Lam, S. G. Mhaisalkar, and M. Srinivasan, Energy Environ. Sci. 4, 413 (2011). 
${ }^{9}$ Z. Zhang, X. Chen, P. Chen, G. Guan, L. Qiu, H. Lin, Z. Yang, W. Bai, Y. Luo, and H. Peng, Adv. Mater. 26, 466 (2014).

${ }^{10}$ C.-T. Chien, P. Hiralal, D.-Y. Wang, I. S. Huang, C.-C. Chen, C.-W. Chen, and G. A. J. Amaratunga, Small 11, 2929 (2015).

11J. Kim, S. M. Lee, Y.-H. Hwang, S. Lee, B. Park, J.-H. Jang, and K. Lee, J. Mater. Chem. A 5, 1906 (2017).

${ }^{12}$ R. Liu, M. Takakuwa, A. Li, D. Inoue, D. Hashizume, K. Yu, S. Umezu, K. Fukuda, and T. Someya, Adv. Energy Mater. 10, 2000523 (2020).

${ }^{13}$ Y. Jin, Z. Li, L. Qin, X. Liu, L. Mao, Y. Wang, F. Qin, Y. Liu, Y. Zhou, and F. Zhang, Adv. Mater. Interfaces 4, 1700704 (2017).

${ }^{14}$ Y. Cui, H. Yao, J. Zhang, K. Xian, T. Zhang, L. Hong, Y. Wang, Y. Xu, K. Ma, C. An, C. He, Z. Wei, F. Gao, and J. Hou, Adv. Mater. 32, 1908205 (2020).

${ }^{15} \mathrm{~N}$. Choudhary, C. Li, J. Moore, N. Nagaiah, L. Zhai, Y. Jung, and J. Thomas, Adv. Mater. 29, 1605336 (2017).

${ }^{16}$ C. J. Zhang, B. Anasori, A. Seral-Ascaso, S. H. Park, N. McEvoy, A. Shmeliov, G. S. Duesberg, J. N. Coleman, Y. Gogotsi, and V. Nicolosi, Adv. Mater. 29 (2017).

${ }^{17}$ Z. Tian, X. Tong, G. Sheng, Y. Shao, L. Yu, V. Tung, J. Sun, R. B. Kaner, and Z. Liu, Nat. Commun. 10, 4913 (2019).

${ }^{18}$ M. Naguib, M. Kurtoglu, V. Presser, J. Lu, J. Niu, M. Heon, L. Hultman, Y. Gogotsi, and M. W. Barsoum, Adv. Mater. 23, 4248 (2011).

${ }^{19}$ S. Tu, Q. Jiang, X. Zhang, and H. N. Alshareef, Appl. Phys. Lett. 114, 232903 (2019).

${ }^{20}$ Z. F. Li, Y. Liang, Z. C. Zhong, J. Y. Qian, G. J. Liang, K. Zhao, H. X. Shi, S. M. Zhong, Y. Z. Yin, and W. J. Tian, Synth. Met. 210, 363 (2015).

${ }^{21}$ Z. F. Li, F. Qin, T. F. Liu, R. Ge, W. Meng, J. H. Tong, S. X. Xiong, and Y. H. Zhou, Org. Electron. 21, 144 (2015).

${ }^{22}$ C. Yeon, S. J. Yun, J. Kim, and J. W. Lim, Adv. Electron. Mater. 1, 1500121 (2015).

${ }^{23}$ Y. Wang, C. Zhu, R. Pfattner, H. Yan, L. Jin, S. Chen, F. Molina-Lopez, F. Lissel, J. Liu, N. I. Rabiah, Z. Chen, J. W. Chung, C. Linder, M. F. Toney, B. Murmann, and Z. Bao, Sci. Adv. 3, e1602076 (2017).

${ }^{24}$ G. Cai, P. Darmawan, M. Cui, J. Wang, J. Chen, S. Magdassi, and P. S. Lee, Adv. Energy Mater. 6, 1501882 (2016).

${ }^{25}$ M. Zhang, Q. Zhou, J. Chen, X. Yu, L. Huang, Y. Li, C. Li, and G. Shi, Energy Environ. Sci. 9, 2005 (2016).

${ }^{26}$ Z. F. Li, G. Q. Ma, R. Ge, F. Qin, X. Y. Dong, W. Meng, T. F. Liu, J. H. Tong, F. Y. Jiang, Y. F. Zhou, K. Li, X. Min, K. F. Huo, and Y. H. Zhou, Angew. Chem. Int. Ed. 55, 979 (2016).

${ }^{27}$ B. Minnaert and P. Veelaert, Energies 7, 1500 (2014). 
FIG. 1. (a) Schematic structure of the OPVM (cross-sectional view). (b) $J-V$ characteristic of the OPVM with 5 cells under 1 Sun condition.

FIG. 2. Electrochemical performances of the ASCs. (a) The Device configuration of solidstate ASCs based on PEDOT:PSS and $\mathrm{Ti}_{3} \mathrm{C}_{2} \mathrm{~T}_{\mathrm{x}}$ electrodes. (b) $\mathrm{CV}$ curves of PEDOT:PSS and $\mathrm{Ti}_{3} \mathrm{C}_{2} \mathrm{~T}_{\mathrm{x}}$ electrodes at a scan rate of $50 \mathrm{mV} \mathrm{s}^{-1}$. (c) $\mathrm{CV}$ curves of ASCs at different voltage windows at the scan rate of $100 \mathrm{mV} \mathrm{s}^{-1}$. (d) CV curves of ASCs at different scan rates from 10 to $200 \mathrm{mV} \mathrm{s}^{-1}$. (e) GCD profiles of ASCs at different current densities. (f) The areal capacitance of ASCs calculated from the GCD profiles.

FIG. 3. Device structure and working process of the IPC.

FIG. 4. (a) Emission power and integrated power spectra of the LED light source at 45000 lux. (b) Photo-charge of the IPC under LED light source at 45000 lux and galvanostatic discharge at different discharge current densities in dark. (c) The comparison of the areal capacitance of the ASCs before integrated and after integration. Inset is the photograph of the IPC. (d) Photo-charge of the IPC under LED light source at 1000 lux and galvanostatic discharge at $0.5 \mathrm{~mA} \mathrm{~cm}^{-2}$. (e) The $\eta_{\text {overall }}$ of the IPC versus the photo-charge time under an LED light source at 45000 lux. (f) Photographs showing that IPC could power a digital thermometer. 


\section{Supporting Information}

\section{Solution-processed solar-charging power units made of organic photovoltaic modules and asymmetric super-capacitors}

Yingzhi Jin ${ }^{\mathrm{a}, \mathrm{c}}$, Lulu Sun ${ }^{\mathrm{b}}$, Leiqiang Qin ${ }^{\mathrm{a}}$, Yanfeng Liu ${ }^{\mathrm{a}}$, Zaifang $\mathrm{Li}^{\mathrm{c}, *}$, Yinhua $\mathrm{Zhou}^{\mathrm{b}, *}$, and Fengling Zhang $^{\mathrm{a}, *}$

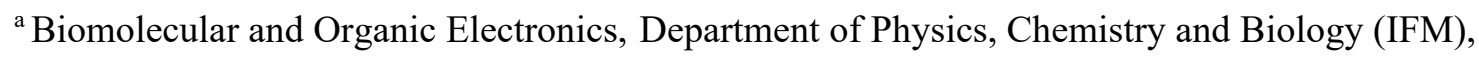
Linköping University, SE-58183 Linköping, Sweden

${ }^{\mathrm{b}}$ Wuhan National Laboratory for Optoelectronics, and School of Optical and Electronic Information, Huazhong University of Science and Technology, Wuhan 430074, China

${ }^{\mathrm{c}}$ China-Australia Institute for Advanced Materials and Manufacturing, Jiaxing University, Jiaxing 314001, P. R. China

Authors to whom correspondence should be addressed:zaifang.li@zjxu.edu.cn, yh_zhou@hust.edu.cn, fengling.zhang@liu.se

\section{Experimental Section}

PBDB-T and ITIC were purchased from The Organtecsolar Materials Inc. PH1000 was purchased from Hereaus. Zinc acetate dehydrate, methoxyethanol, ethanolamine, sulfuric acid $\left(\mathrm{H}_{2} \mathrm{SO}_{4}\right)$ (95 wt.\%), ethylene glycol (EG), Polyvinyl alcohol (PVA) (Mw = 130,000 g/mol; 98 99 mol\% hydrolysed) and 1,8-diiodooctane (DIO) were purchased from Sigma-Aldrich.

The current density-voltage $(J-V)$ curves were measured by using a Keithley 2400 Source Meter under an illumination of AM 1.5G simulated by a Newport solar simulator. The electrochemical tests were performed using an Autolab PGSTAT $302 \mathrm{~N}$ (Metrohm AG, Netherlands).

The free-standing PEDOT:PSS films were obtained by vacuum-filtered PH1000 suspension onto nano-porous polypropylene membranes (Celgard 3501, $0.064 \mu \mathrm{m}$ pore size, Celgard LLC), which could avoid the penetration of the PH1000 suspension. The thickness of the free-standing PEDOT:PSS films were tuned by the volume of the PH1000 suspension. Then 
the films were soaked into the concentrated $\mathrm{H}_{2} \mathrm{SO}_{4}$ for $24 \mathrm{~h}$ to improve the conductivity. The treated films were washed with deionized water three times and dried in vacuum.

$\mathrm{Ti}_{3} \mathrm{C}_{2} \mathrm{~T}_{\mathrm{x}}$ MXene was produced according to the previously report. ${ }^{1} \mathrm{Ti}_{3} \mathrm{C}_{2} \mathrm{~T}_{\mathrm{x}}$ electrode was fabricated through vacuum filtration from $\mathrm{Ti}_{3} \mathrm{C}_{2} \mathrm{~T}_{\mathrm{x}}$ colloidal solution with $5 \mathrm{mg} \mathrm{mL}^{-1}$ onto nanoporous polypropylene membranes (Celgard 3501, $0.064 \mu \mathrm{m}$ pore size, Celgard LLC).

The OPVM with a subcell configuration of ITO/ZnO/PBDB-T:ITIC/PEDOT:PSS was fabricated as following: the ITO substrates were patterned by laser ablation (KW FIB $20 \mathrm{w}$, Kewei laser). The patterned ITO substrates were cleaned by a sequential ultrasonic procedure in detergent, deionized water, and isopropanol. $\mathrm{ZnO}$ sol-gel solution was spin-coated on the patterned ITO substrate at $4000 \mathrm{rpm}$ for $45 \mathrm{~s}$, followed by a thermal annealing at $200{ }^{\circ} \mathrm{C}$ for 15 min in air. The active layer consists of PBDB-T and ITIC (10 mg, $10 \mathrm{mg})$ in chlorobenzene $(1 \mathrm{~mL})$ with $0.5 \%$ DIO was spin-coated on the top of $\mathrm{ZnO}$ at $1500 \mathrm{rpm}$ for $60 \mathrm{~s}$ in glove box followed by annealing at $160{ }^{\circ} \mathrm{C}$ for $10 \mathrm{~min}$. To have the connection between the top and bottom electrodes of the adjacent cells, the active layer and $\mathrm{ZnO}$ at the connection position were removed. The detail of the transfer lamination method was reported in our previous report. ${ }^{2}$ The PH1000 suspension with 5\% EG was spin-coated on the plasma-treated polydimethylsiloxane (PDMS) films (3 min) at $1000 \mathrm{rpm}$ for $60 \mathrm{~s}$. The PDMS with PEDOT:PSS electrodes were transferred onto the top of the plasma-treated active layer (10 s). Then, PDMS films were slowly peeled off. Silver (Ag) pastes were used to connect the top and bottom electrodes of the adjacent cells. Finally, the transparent OPVM was dried in vacuum. The effective area of the OPVM was around $2.3 \mathrm{~cm}^{2}$.

The electrochemical properties of the PEDOT:PSS and $\mathrm{Ti}_{3} \mathrm{C}_{2} \mathrm{~T}_{\mathrm{x}}$ electrodes were measured in the three-electrode configuration. The PEDOT:PSS or $\mathrm{Ti}_{3} \mathrm{C}_{2} \mathrm{~T}_{\mathrm{x}}$ films were directly used as working electrode. A piece of Celgard paper was put in between the working and counter 
electrode (glassy carbon electrode) as the separator. The reference electrode was $\mathrm{Ag} / \mathrm{AgCl}$ in 1 $\mathrm{M} \mathrm{KCl}$ and the electrolyte was $1 \mathrm{M} \mathrm{H}_{2} \mathrm{SO}_{4}$ solution.

The all solid-state asymmetric super-capacitors (ASCs) were fabricated by coating $\mathrm{H}_{2} \mathrm{SO}_{4}$ PVA gel electrolyte on the top of PEDOT:PSS and $\mathrm{Ti}_{3} \mathrm{C}_{2} \mathrm{~T}_{\mathrm{x}}$ electrodes and drying in ventilation for $1 \mathrm{~h}$. Then the two electrodes were pressed together. The electrolyte was cured and acted as a glue to hold the device and improve mechanical stability. The $\mathrm{H}_{2} \mathrm{SO}_{4}-\mathrm{PVA}$ gel electrolyte was prepared by dissolving PVA power $(1 \mathrm{~g})$ into deionized water $(10 \mathrm{~mL})$. The mixture was heated to $85{ }^{\circ} \mathrm{C}$ under stirring until the solution became clear. Then concentrated $\mathrm{H}_{2} \mathrm{SO}_{4}(98 \%, 1 \mathrm{~g})$ was added to the solution and stirred for $30 \mathrm{~min}$. The $\mathrm{H}_{2} \mathrm{SO}_{4}-\mathrm{PVA}$ gel electrolyte was used after cooling down to room temperature.

To fabricate the integrated self-power pack, the free-standing PEDOT:PSS electrode was connected with the top electrode (PEDOT:PSS) of OPVM. The bottom electrode of OPVM was connected with another electrode $\left(\mathrm{Ti}_{3} \mathrm{C}_{2} \mathrm{~T}_{\mathrm{x}}\right)$ of the ASCs by a wire.

In order to evaluate the electrochemical properties of the free-standing PEDOT:PSS electrode, cyclic voltammetry (CV) and galvanostatic charge/discharge (GCD) measurements are conducted in a three electrode setup using $1 \mathrm{M} \mathrm{H}_{2} \mathrm{SO}_{4}$ as electrolyte. As shown in Fig. S1a, the $\mathrm{CV}$ curves are recorded at different scan rates with potential window from -0.2 to $0.8 \mathrm{~V}$ vs. $\mathrm{Ag} / \mathrm{AgCl}$. The near rectangle shape of the $\mathrm{CV}$ curves even at a high scan rate of $200 \mathrm{mV} \mathrm{s}^{-1}$ indicated the excellent capacitive and high conductivity of the free-standing PEDOT:PSS electrode. The GCD profiles at different current densities are shown in Fig. S1b. The near triangular shapes of these curves indicate high reversibility of the charging/discharging process, which is in good agreement with the $\mathrm{CV}$ results. The areal capacitances $\left(C_{\mathrm{A}}\right)$ under different current densities are displayed in Fig. S1c, which are calculated from the GCD profiles through Equation S1. At $0.5 \mathrm{~mA} \mathrm{~cm}^{-2}$, a high area capacitance of $214 \mathrm{mF} \mathrm{cm}^{-2}$ is achieved, even at the 
current density of $8 \mathrm{~mA} \mathrm{~cm}^{-2}$, it yields a high capacitance of $204 \mathrm{mF} \mathrm{cm}^{-2}$, indicating the superior rate performance of free-standing PEDOT:PSS electrode.

$$
C_{\mathrm{A}}=\frac{I \Delta t}{\Delta V}
$$

where $I$ is the applied current density $\left(\mathrm{mA} \mathrm{cm}^{-2}\right), \Delta t$ is the discharge time (s), $\Delta V$ is the operating voltage obtained from the discharge profile excluding the voltage drop (V).
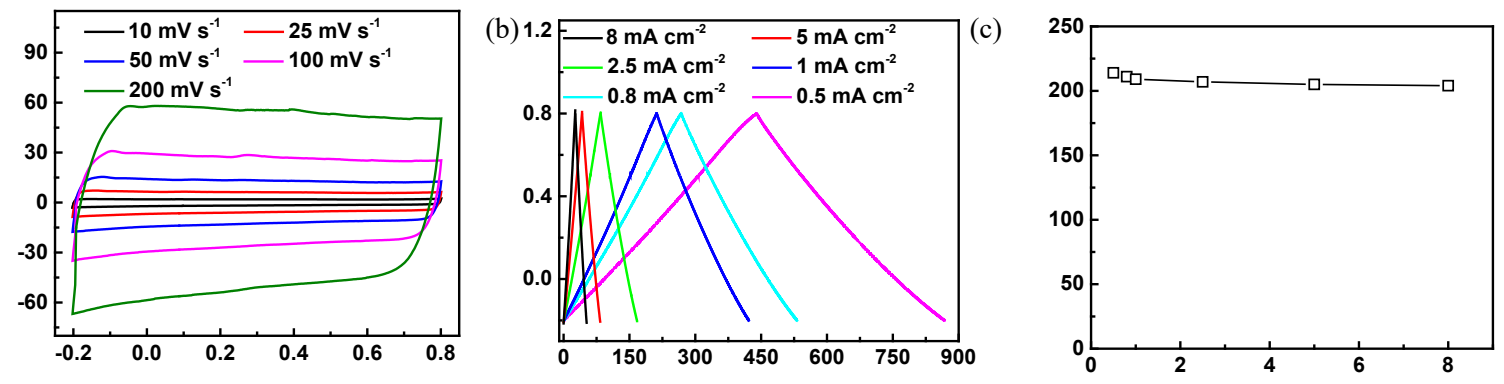

FIG. S1. Electrochemical performances of PEDOT:PSS electrode. (a) CV curves of PEDOT:PSS electrode at different scan rate of 10, 25, 50, 100, and $200 \mathrm{mV} \mathrm{s}^{-1}$. (b) GCD profiles of PEDOT:PSS electrode at different current density. (c) Areal capacitance of PEDOT:PSS electrode as a function of current density.

The free-standing $\mathrm{Ti}_{3} \mathrm{C}_{2} \mathrm{~T}_{\mathrm{x}}$ film is prepared by vacuum filtration. The electrochemical performance of $\mathrm{Ti}_{3} \mathrm{C}_{2} \mathrm{~T}_{\mathrm{x}}$ electrode is also performed in the three electrode setup using $1 \mathrm{M}$ $\mathrm{H}_{2} \mathrm{SO}_{4}$ as electrolyte. The $\mathrm{CV}$ curves of $\mathrm{Ti}_{3} \mathrm{C}_{2} \mathrm{~T}_{\mathrm{x}}$ electrode are recorded at different scan rates with potential window from -0.7 to $0.2 \mathrm{~V}$ vs. $\mathrm{Ag} / \mathrm{AgCl}$ (Fig. S2a). The areal capacitances from the $\mathrm{CV}$ curves are determined from the following equation (S2):

$$
C_{A}=\frac{1}{\Delta V} \int \frac{j d V}{s}
$$

where $j$ is the current density $\left(\mathrm{mA} \mathrm{cm}^{-2}\right), s$ is the rate $\left(\mathrm{V} \mathrm{s}^{-1}\right), V$ is the voltage $(\mathrm{V}), \Delta V$ is the operating voltage window (V). 
As shown in Fig. S3a, obvious redox peaks were displayed at low scan rate, which is indicative of the pseudocapacitive behaviour of $\mathrm{Ti}_{3} \mathrm{C}_{2} \mathrm{~T}_{\mathrm{x}}$. While increasing the scan rate, the redox peaks are shifted and become non-obvious. The capacitive effects of the $\mathrm{Ti}_{3} \mathrm{C}_{2} \mathrm{~T}_{\mathrm{x}}$ electrodes are investigated by measuring how the peak currents $\left(i_{p}\right)$ changed with the scan rates $(s)$. Assuming that the peak currents obey the power law, 3,4

$$
i_{p}=a s^{b}
$$

where $a$ and $b$ were variables, $b$-value of 0.5 indicated diffusion limited reactions and $b=1$ indicated surface-controlled (capacitive) reactions. Fig. S3b presented the $\log \left(\mathrm{i}_{\mathrm{p}}\right)-\log (s)$ plots from 5 to $200 \mathrm{mV} \mathrm{s}^{-1}$ for both cathodic and anodic peak currents and the corresponding b-values. At scan rates ranging from 5 to $50 \mathrm{mV} \mathrm{s}^{-1}$, the $\mathrm{b}$-values for the cathodic and anodic peak currents were 0.89 and 0.96 (close to 1), respectively, indicating the surface-controlled reactions. While at scan rates ranging from 50 to $200 \mathrm{mV} \mathrm{s}^{-1}$, the slope of both cathodic and anodic peak currents changed, resulting in a decrease in b-values to 0.75 and 0.65 , respectively. This limitation to the rate capability could be attributed to more diffusion limited reactions dominated in the high scan rates. The GCD profiles of the $\mathrm{Ti}_{3} \mathrm{C}_{2} \mathrm{~T}_{\mathrm{x}}$ electrode at different current densities shown near symmetric triangular shapes of these curves including an obvious redox signal at around $-0.2 \mathrm{~V}$ (Fig. S3c), indicating high reversibility of the charging/discharging process. The areal capacitances under different current densities are displayed in Fig. S3d. At $0.5 \mathrm{~mA} \mathrm{~cm}^{-2}$, a high area capacitance of $384 \mathrm{mF} \mathrm{cm}^{-2}$ is achieved, even at the current density of $5 \mathrm{~mA} \mathrm{~cm}^{-2}$, it yields a high capacitance of $331 \mathrm{mF} \mathrm{cm}$, indicating the superior rate performance of the $\mathrm{Ti}_{3} \mathrm{C}_{2} \mathrm{~T}_{\mathrm{x}}$ electrode. 

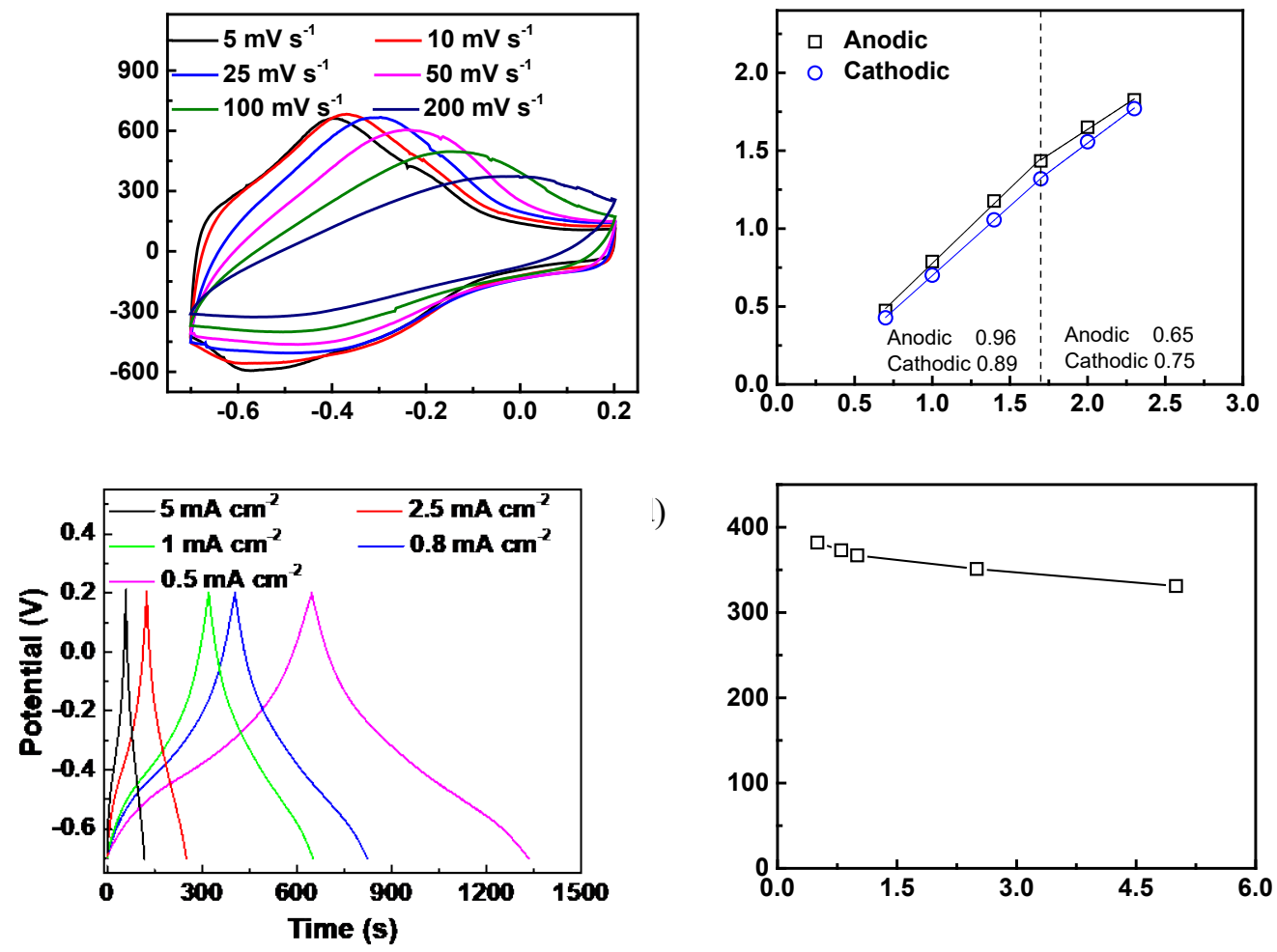

FIG. S2. Electrochemical performances of $\mathrm{Ti}_{3} \mathrm{C}_{2} \mathrm{~T}_{\mathrm{x}}$ electrode. (a) $\mathrm{CV}$ curves of $\mathrm{Ti}_{3} \mathrm{C}_{2} \mathrm{~T}_{\mathrm{x}}$ electrode at different scan rates from 5 to $200 \mathrm{mV} \mathrm{s}^{-1}$. (b) $\log \left(\mathrm{i}_{\mathrm{p}}\right)-\log (s)$ plot for $\mathrm{Ti}_{3} \mathrm{C}_{2} \mathrm{~T}_{\mathrm{x}}$ electrode at different scan rates from 5 to $200 \mathrm{mV} \mathrm{s}^{-1}$. b-values for both anodic and cathodic peak currents are listed in the Figure. (c) GCD profiles of $\mathrm{Ti}_{3} \mathrm{C}_{2} \mathrm{~T}_{\mathrm{x}}$ electrode at different current density. (d) Areal capacitance of $\mathrm{Ti}_{3} \mathrm{C}_{2} \mathrm{~T}_{x}$ electrode calculated from the GCD profiles. 

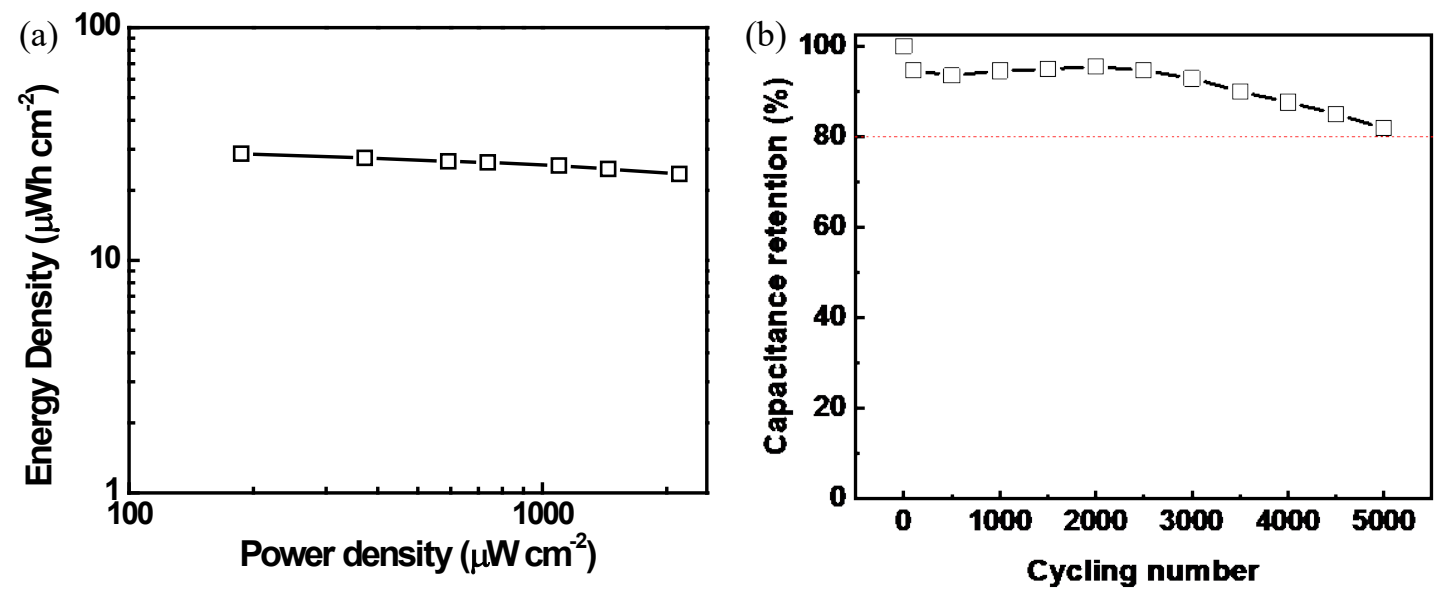

FIG. S3. (a) Ragone plots: energy and power density of the ASCs. (b) Cyclic stability of the ASCs.

(a)
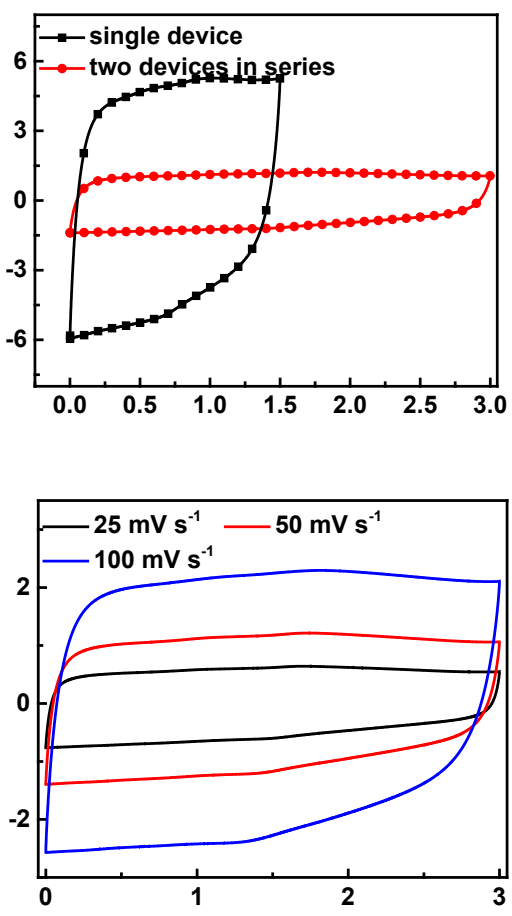
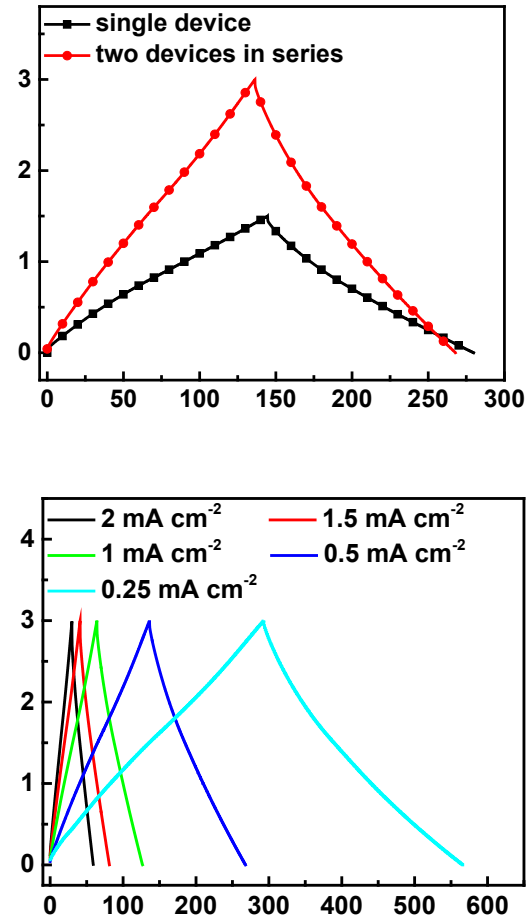

FIG. S4. (a) CV curves of single ASCs and two devices connected in series at a scan rate of 50 $\mathrm{mV} \mathrm{s}^{-1}$. (b) GCD profiles of single ASCs and two devices connected in series at a current of 1.6 mA. (c) CV curves of two series connected ASCs at different scan rates. (d) GCD profiles of two series connected ASCs at different current densities. 

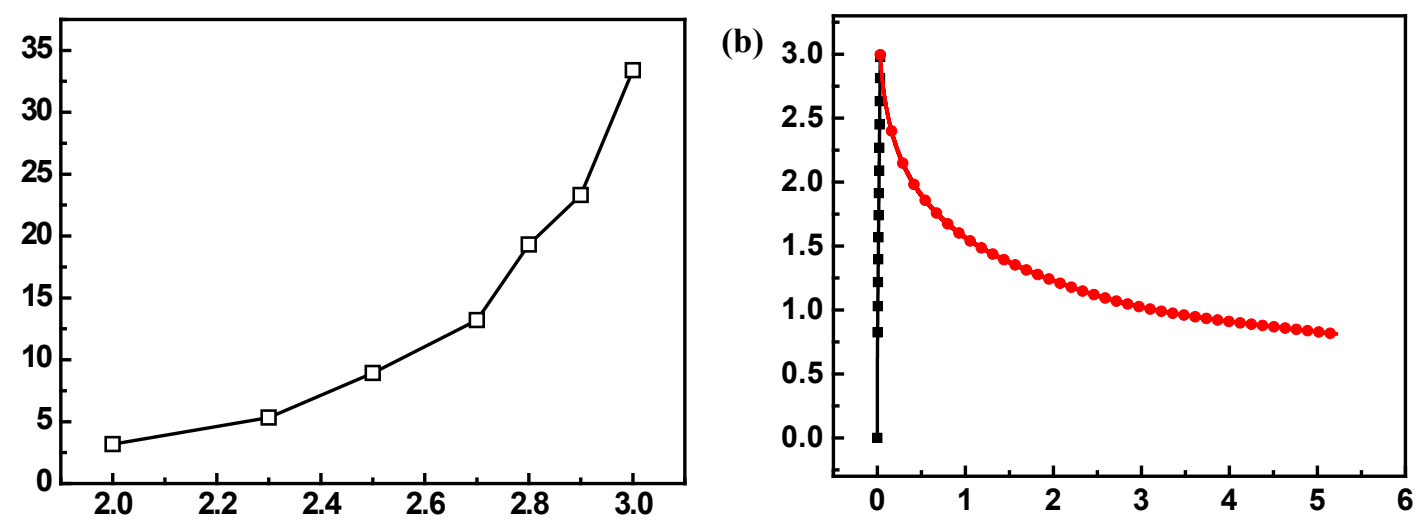

FIG. S5. (a) The leakage current density as a function of charge potential of the series connected ACSs. (b) Self-discharge behavior of the series connected ACSs.

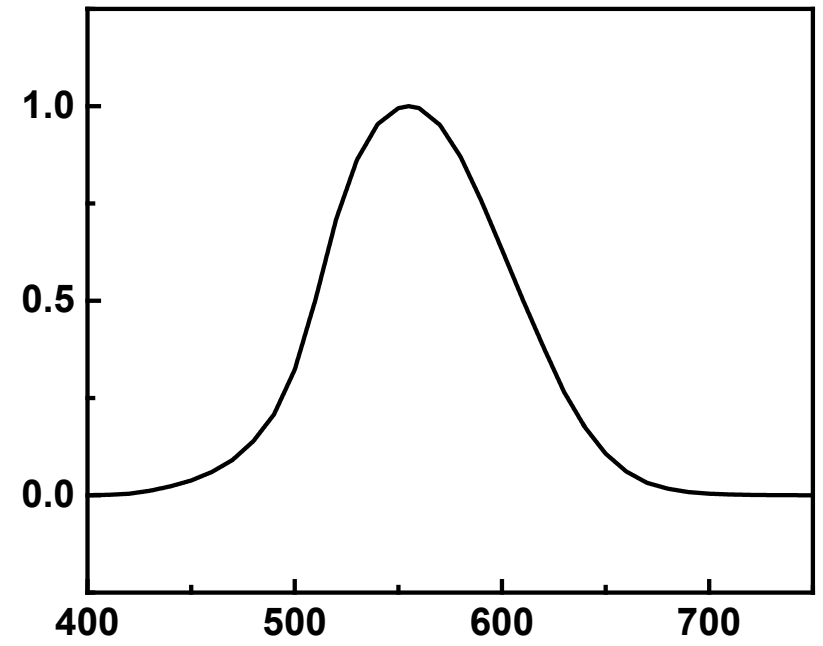

FIG. S6. The spectral luminosity function. 


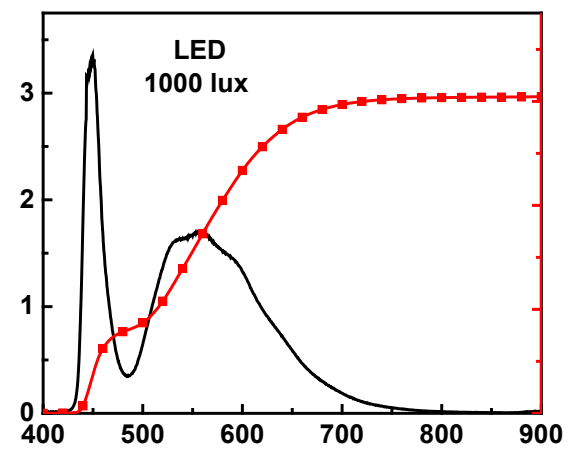

(b)

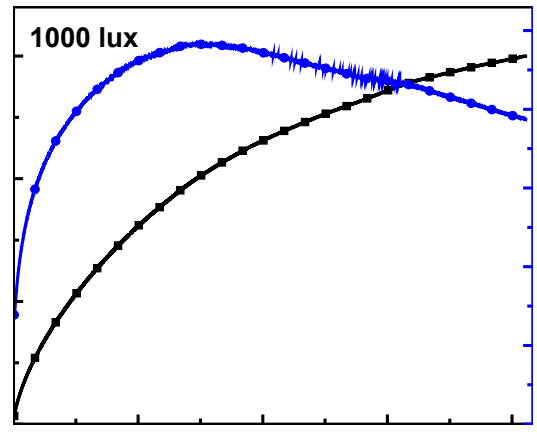

FIG. S7. (a) Emission power and integrated power spectra of the LED light source at 1000 lux. (b) The overall efficiency of the IPC versus the photo-charge time under LED light source at 1000 lux.
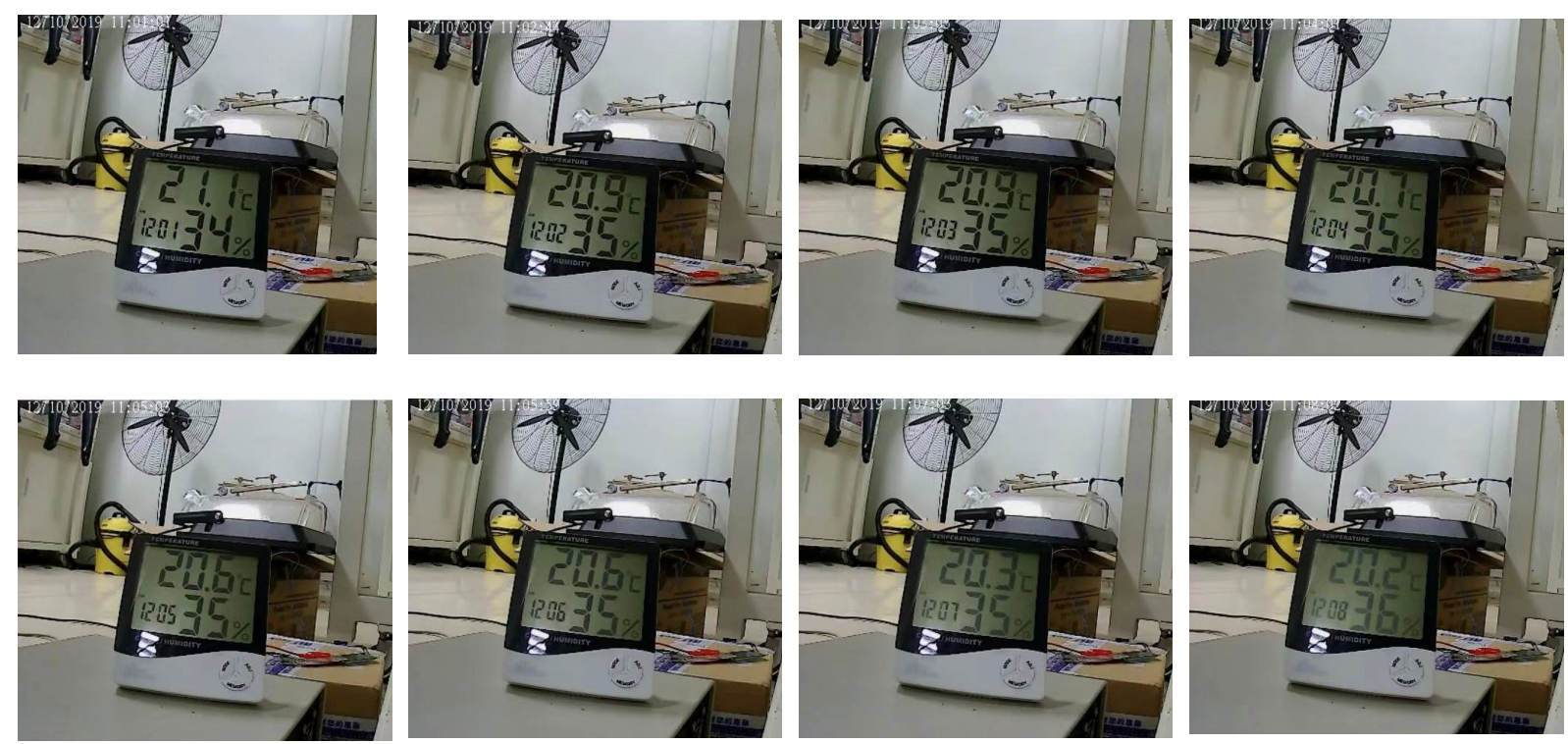

FIG. S8. Photographs showing that IPC could power a digital thermometer for about 8 min. 

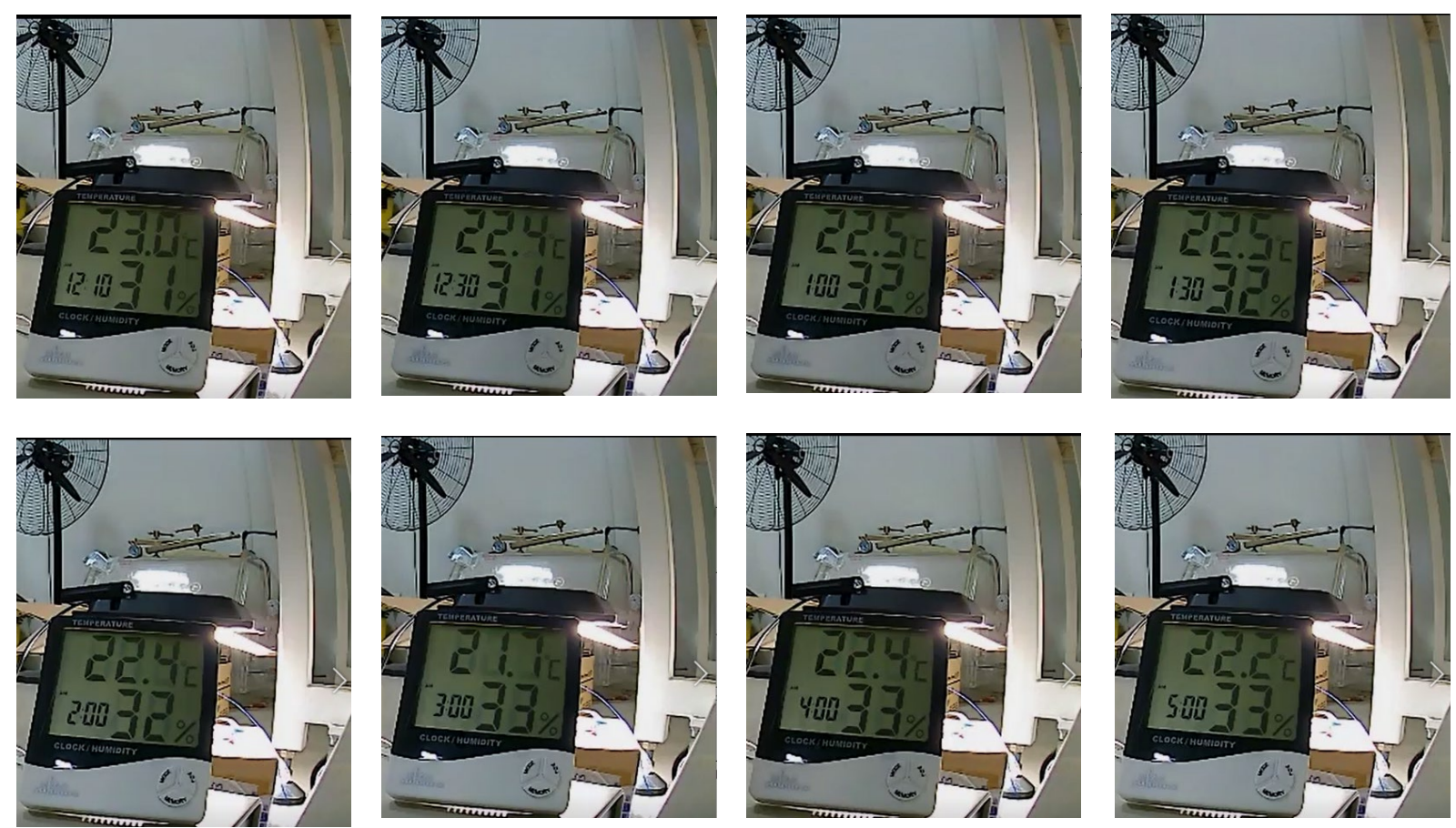

FIG. S9. The IPC under LED light source at 500 lux could continuously power the digital thermometer for $5 \mathrm{~h}$. 
TABLE S1. Performance comparison of the output voltage and overall efficiency between our IPC and other IPCs based on OPVs.

\begin{tabular}{|c|c|c|c|c|}
\hline System & Electrolyte & Voltage (V) & $\begin{array}{l}\text { Overall } \\
\text { efficiency }\end{array}$ & Ref. \\
\hline PEDOT:PSS// $\mathrm{Ti}_{3} \mathrm{C}_{2} \mathrm{~T}_{\mathrm{x}}$ & $\mathrm{H}_{2} \mathrm{SO}_{4}-\mathrm{PVA}$ & 3 & $6.0 \%$ & This work \\
\hline $\begin{array}{l}\text { Single-walled carbon } \\
\text { nanotube (CNT) network }\end{array}$ & $\mathrm{H}_{3} \mathrm{PO}_{4}-\mathrm{PVA}$ & 1 & - & 5 \\
\hline $\begin{array}{l}\text { Multi-walled carbon nanotube } \\
\text { (MWCNT) sheets }\end{array}$ & $\mathrm{H}_{3} \mathrm{PO}_{4}-\mathrm{PVA}$ & 0.4 & $0.82 \%$ & 6 \\
\hline Graphene & $\mathrm{Et}_{4} \mathrm{NBF}_{4}$ & 4 & - & 7 \\
\hline Carbon-black & $\mathrm{BMIM} \mathrm{BF}_{4}$ & 0.53 & $2.92 \%$ & 8 \\
\hline PEDOT:PSS & $\mathrm{H}_{3} \mathrm{PO}_{4}-\mathrm{PVA}$ & 0.8 & $2 \%$ & 9 \\
\hline Reduced graphene oxide & $\mathrm{H}_{3} \mathrm{PO}_{4}-\mathrm{PVA}$ & 0.73 & $5.07 \%$ & 10 \\
\hline $\mathrm{Ti}_{3} \mathrm{C}_{2} \mathrm{~T}_{\mathrm{x}}$ & Organic ionogel & 0.8 & $2.2 \%$ & 1 \\
\hline
\end{tabular}




\section{REFERENCES}

${ }^{1}$ L. Qin, J. Jiang, Q. Tao, C. Wang, I. Persson, M. Fahlman, P. O. Å. Persson, L. Hou, J. Rosen, and F. Zhang, J. Mater. Chem. A 8, 5467 (2020).

${ }^{2}$ Y. Wang, B. Jia, F. Qin, Y. Wu, W. Meng, S. Dai, Y. Zhou, and X. Zhan, Polymer 107, 108 (2016).

${ }^{3}$ H. Lindström, S. Södergren, A. Solbrand, H. Rensmo, J. Hjelm, A. Hagfeldt, and S.-E. Lindquist, J. Phys. Chem. B 101, 7717 (1997).

${ }^{4}$ V. Augustyn, J. Come, M. A. Lowe, J. W. Kim, P.-L. Taberna, S. H. Tolbert, H. D. Abruña, P. Simon, and B. Dunn, Nat. Mater. 12, 518 (2013).

${ }^{5}$ G. Wee, T. Salim, Y. M. Lam, S. G. Mhaisalkar, and M. Srinivasan, Energy Environ. Sci. 4, 413 (2011).

${ }^{6} Z$. Zhang, X. Chen, P. Chen, G. Guan, L. Qiu, H. Lin, Z. Yang, W. Bai, Y. Luo, and H. Peng, Adv. Mater. 26, 466 (2014).

${ }^{7}$ C.-T. Chien, P. Hiralal, D.-Y. Wang, I. S. Huang, C.-C. Chen, C.-W. Chen, and G. A. J. Amaratunga, Small 11, 2929 (2015).

${ }^{8}$ B. P. Lechêne, M. Cowell, A. Pierre, J. W. Evans, P. K. Wright, and A. C. Arias, Nano Energy 26, 631 (2016).

${ }^{9}$ Y. Jin, Z. Li, L. Qin, X. Liu, L. Mao, Y. Wang, F. Qin, Y. Liu, Y. Zhou, and F. Zhang, Adv. Mater. Interfaces 4, 1700704 (2017).

${ }^{10}$ J. Kim, S. M. Lee, Y.-H. Hwang, S. Lee, B. Park, J.-H. Jang, and K. Lee, J. Mater. Chem. A 5, 1906 (2017). 
(a)

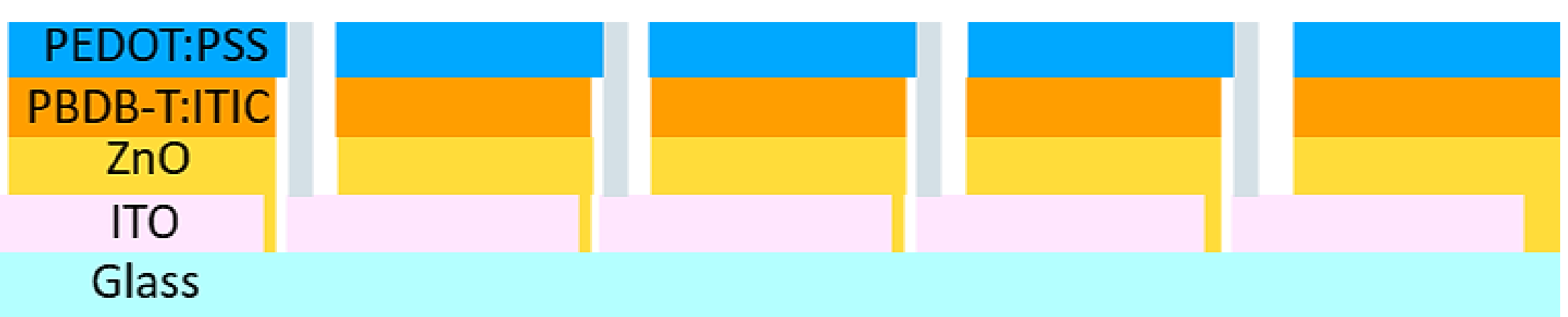

(b)

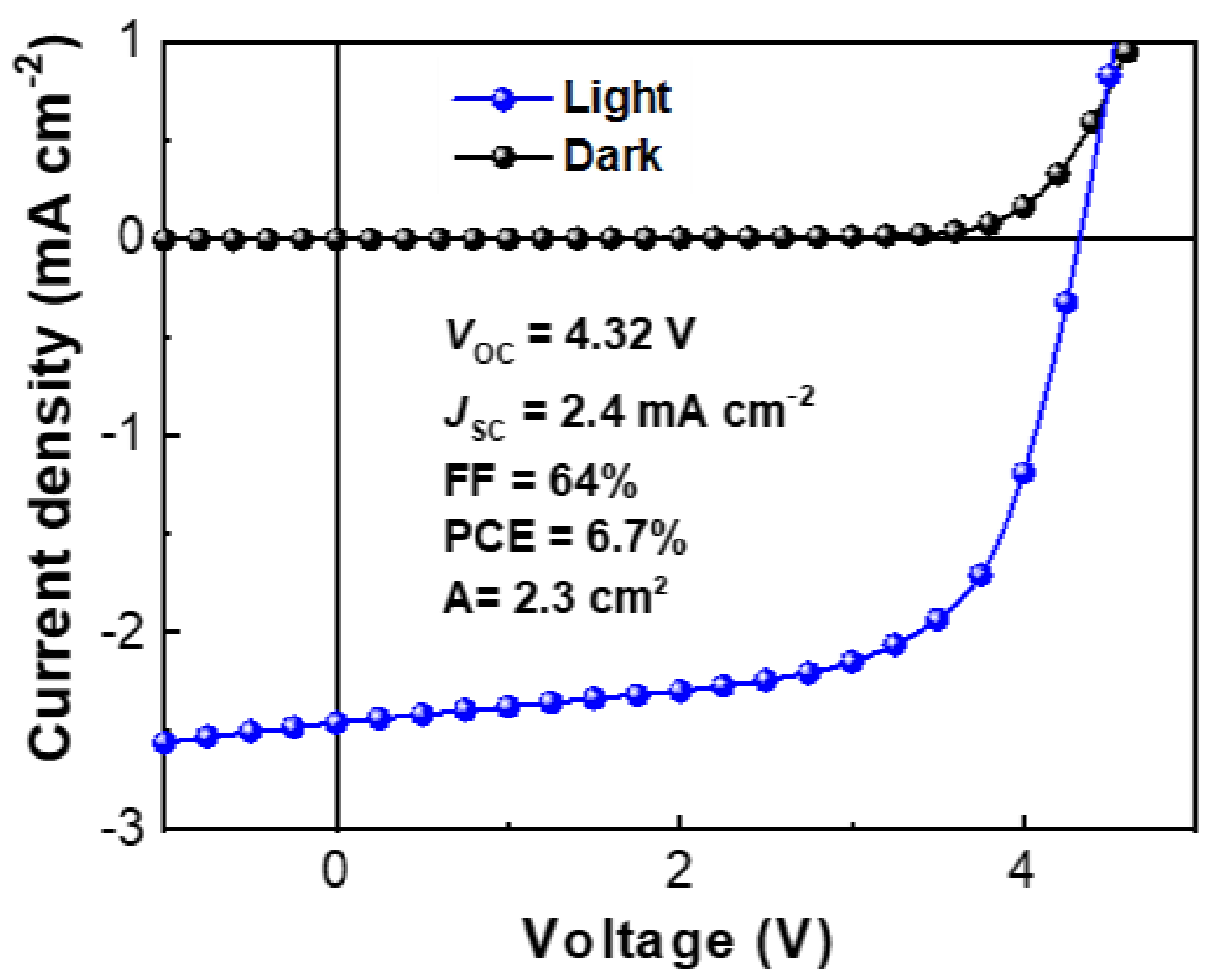


(a)
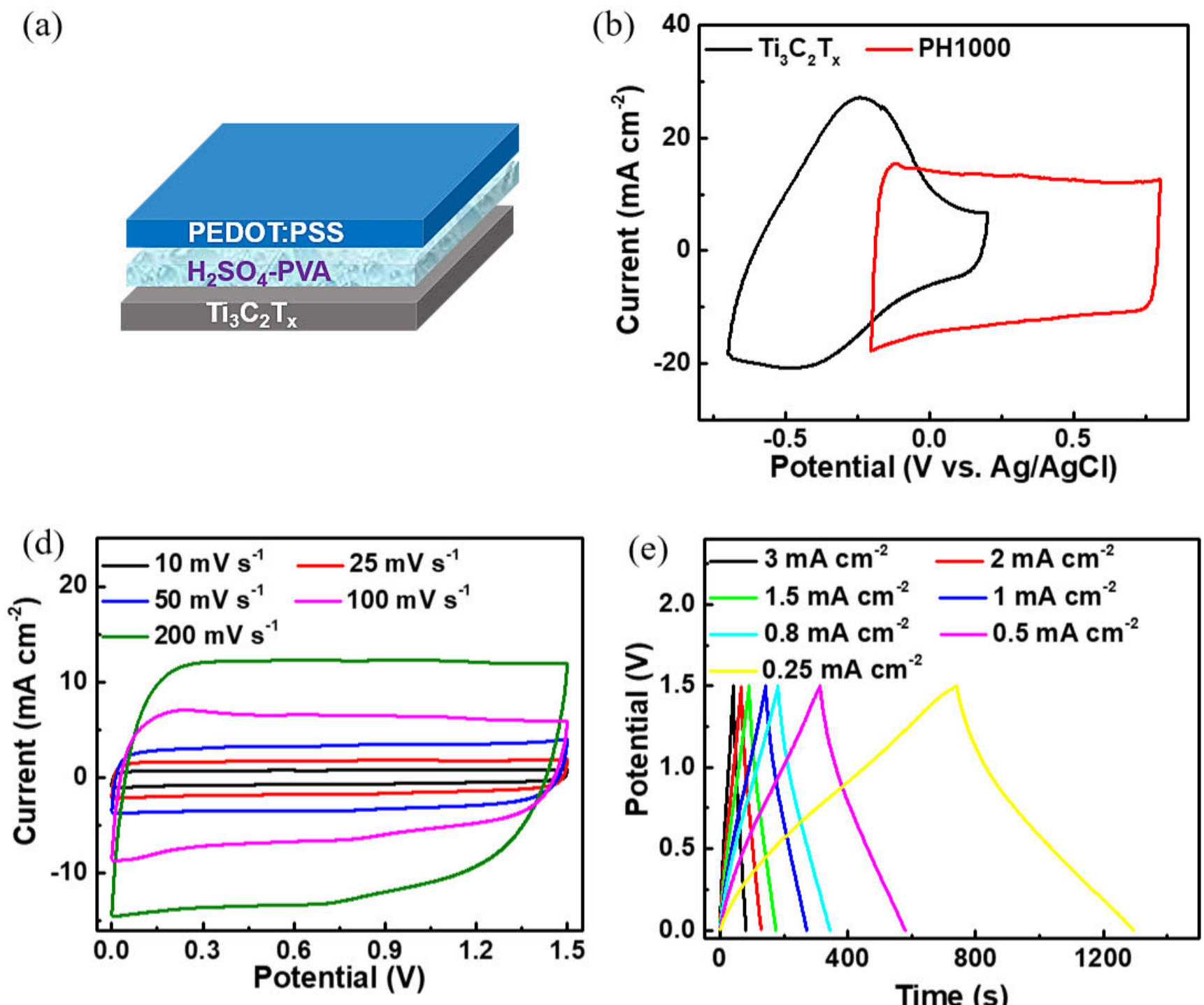
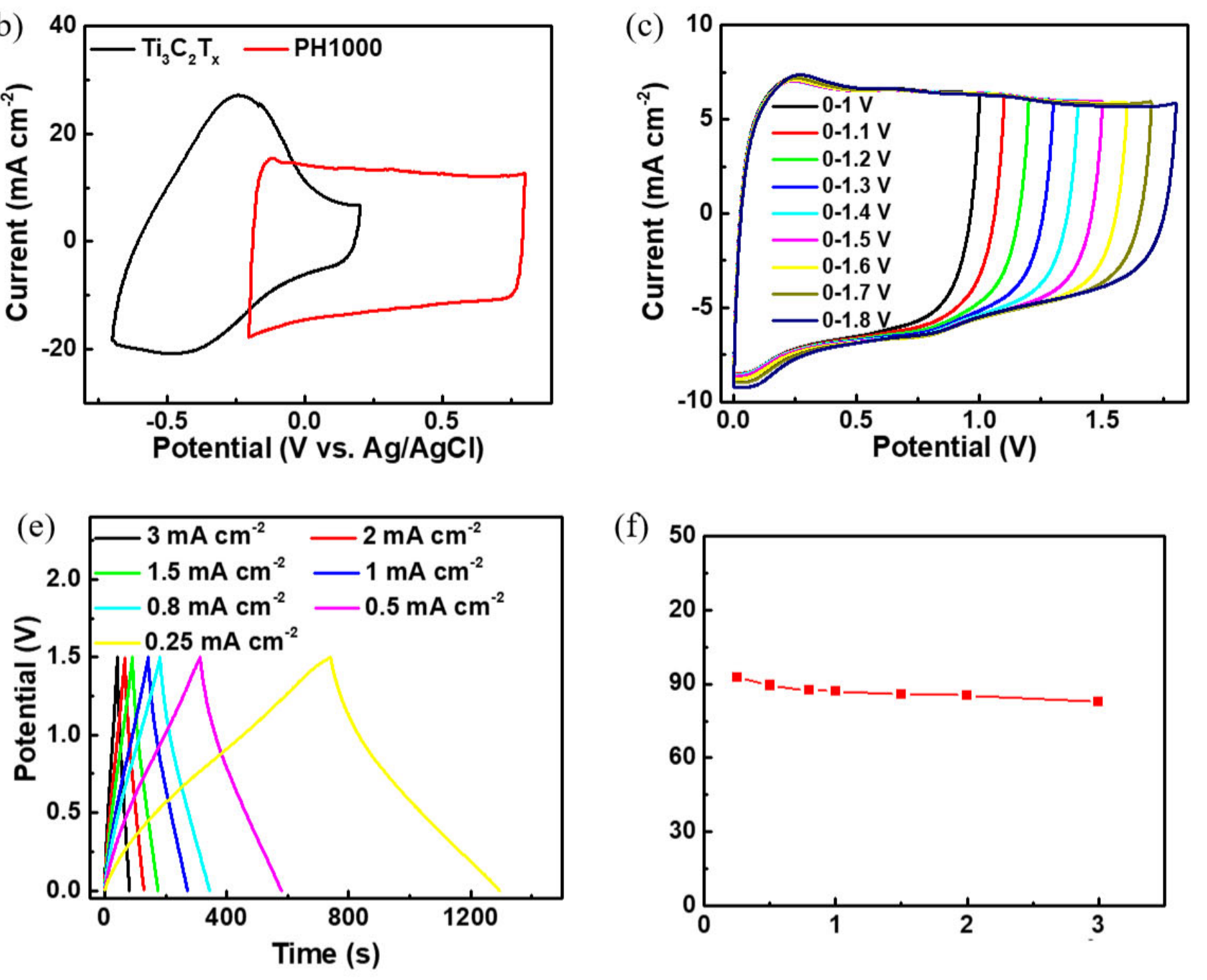

(f)

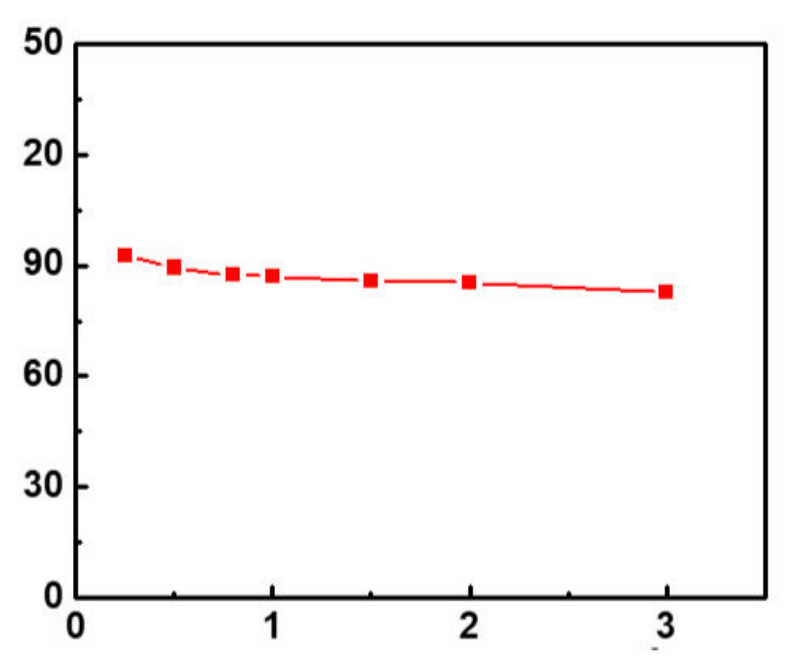




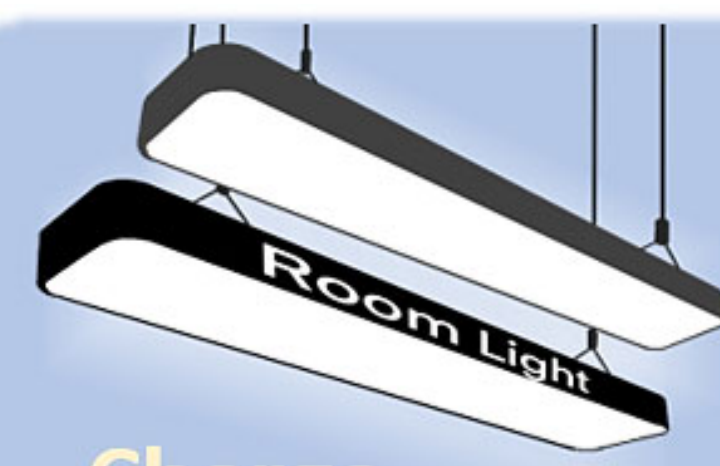

Charge

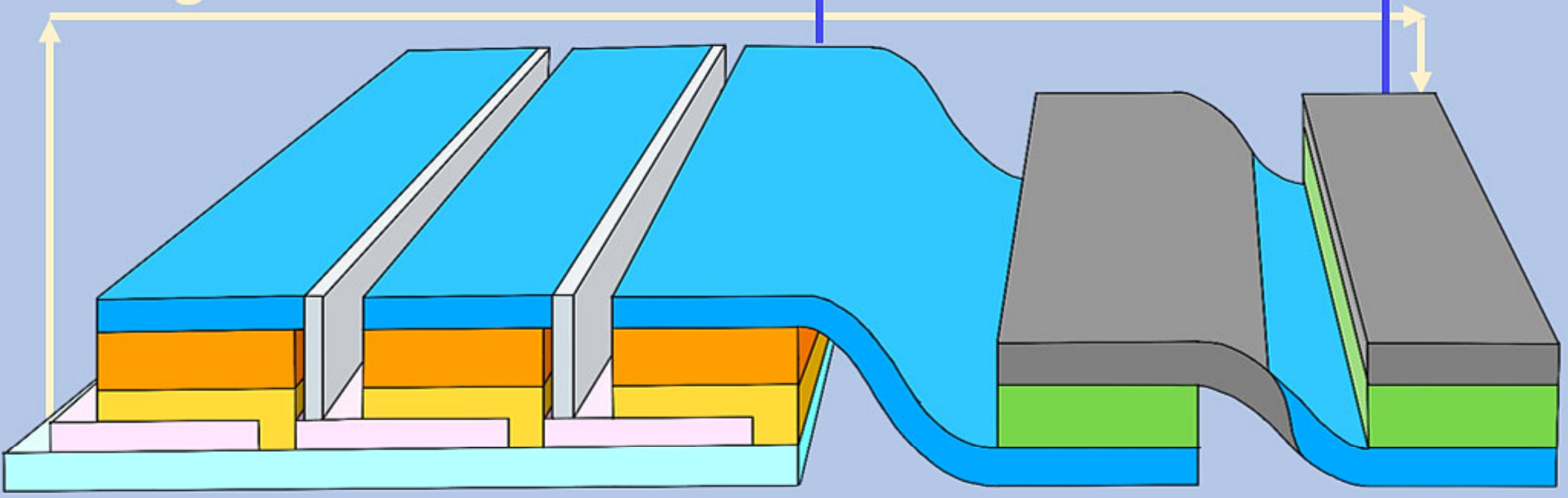

$\square$ PEDOT:PSS $\square$ PBDB-T:ITIC

$\square \mathrm{Ti}_{3} \mathrm{C}_{2} \mathrm{~T}_{\mathrm{x}} \square \mathrm{H}_{2} \mathrm{SO}_{4}-\mathrm{PVA}$

$\square$ ZnO $\square$ ITO $\square$ Glass

$\square$ Silver paste 

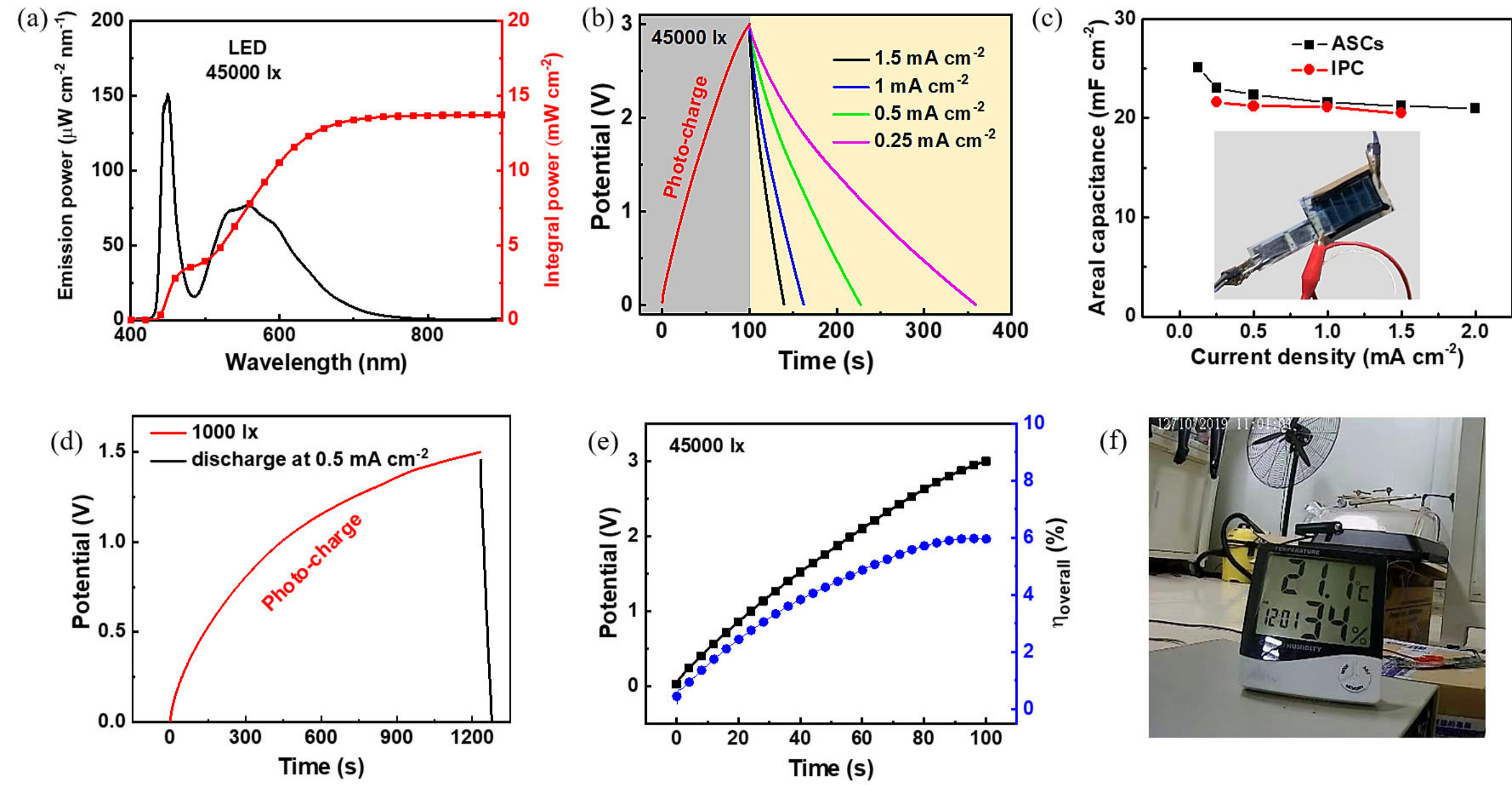

(f)

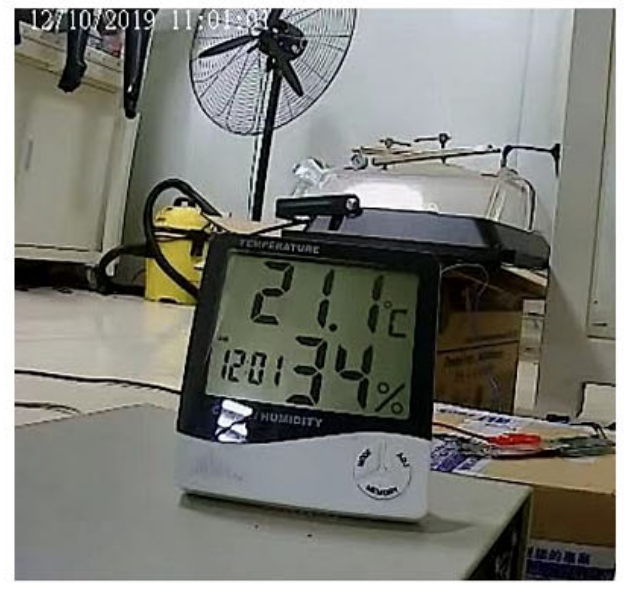

